\title{
KAJIAN PEMBERIAN LEAFLET DAN REMINDER PADA PASIEN HIPERTENSI DI INSTALASI RAWAT JALAN RSUD A. W SJAHRANIE SAMARINDA PERIODE DESEMBER 2014-FEBRUARY 2015
}

\author{
Sheny Clarin Ananta ${ }^{1, *}$, Welinda Dyah Ayu ${ }^{1}$, Rolan Rusli ${ }^{1,2, \dagger}$ \\ ${ }^{1}$ Laboratorium Penelitian dan Pengembangan Kefarmasian "Farmaka Tropis", \\ Fakultas Farmasi, Universitas Mulawarman, Samarinda \\ *Email : clarinananta@rocketmail.com \\ ${ }^{2}$ Kelompok Bidang Ilmu Kimia Farmasi, Fakultas Farmasi, \\ Universitas Mulawarman, Samarinda \\ *Email : rolan@farmasi.unmul.ac.id
}

\begin{abstract}
Hypertension is condition when blood pressure increases from its normally (120/80 $\mathrm{mmHg}$ ). According from $\mathrm{WHO}$, the prevalence of hypertension in global was $40 \%$ and mortality that caused by hypertension was $55 \%$. The management of therapy hypertension and lifestyle modification become important to increase the effectiveness of therapy and reduce the risk of complications. The aim of this research was to determine the difference effect of leaflet and the reminder for blood pressure, adherence medication and behavior of the patients. The research is an experimental study with systematic random sampling. Subject consisted of 50 people divided into 2 groups with intervention. Each group consisted of 25 people. The analysis method used in this research are Wilcoxon and Mann Whitney U. The results showed that there was no difference in systolic blood pressure $(p=0,263)$ and dyastolic blood pressure $(p=0,864)$ between subjects in leaflet group and reminder group. There was difference of adherence medication $(p=0,000)$ betweensubject in leaflet group and reminder group. Behavior of patients at preparation stage after intervention with leaflets and reminders.
\end{abstract}

Key Words: Adherence, Blood pressure, Hypertension, Leaflet, Reminder

\begin{abstract}
ABSTRAK
Hipertensi adalah kondisi dimana tekanan darah meningkat dari tekanan darah normal (120/80 mmHg). Berdasarkan survei dari WHO, prevalensi hipertensi $40 \%$ terjadi pada penduduk global dan $55 \%$ kematian disebabkan oleh hipertensi. Manejemen terapi hipertensi dan modifikasi gaya hidup dapat meningkatkan efektivitas terapi dan menurunkan risiko komplikasi. Tujuan dari penelitian ini
\end{abstract}


untuk melihat perbedaan efek dari leaflet dan reminder terhadap tekanan darah kepatuhan pasien dan perilaku pasien. Penelitian ini adalah studi eksperimen dengan teknik systematic random sampling. Subjek penelitian terdiri dari 50 orang yang dibagi dalam 2 kelompok dengan intervensi. Analisis yang digunakan adalah Wilcoxon and Mann Whitney U. Hasil penelitian didapatkan tidak terdapat perbedaan tekanan darah sistolik $(\mathrm{p}=0,424)$ dan tekanan darah diastolik $(\mathrm{p}=0,831)$ antara subjek pada kelompok leaflet dan subjek pada kelompok reminder. Namun, terdapat perbedaan kepatuhan pasien antara subjek pada kelompok leaflet dan reminder. Perilaku pasien pada tahap preparation stage setelah pemberian leaflet dan reminder.

Kata Kunci: Kepatuhan pasien, tekanan darah, hipertensi, Leaflet, Reminder

\section{PENDAHULUAN}

Hipertensi didefinisikan sebagai kejadian meningkatnya tekanan darah arteri secara terus-menerus. Pasien dengan tekanan darah diastolik $>90 \mathrm{mmHg}$ dan tekanan darah sistolik $\geq 140 \mathrm{mmHg}$ telah tergolong pasien hipertensi [1]. Berdasarkan WHO (world health organisation) hipertensi merupakan penyumbang utama terhadap penyakit global. Angka prevalensi global penduduk dengan hipertensi menjadi sekitar $40 \%$ dan kematian akibat hipertensi sekitar $55 \%$ dari kematian global yang disebabkan oleh penyakit kardiovaskuler. Sedangkan di Indonesia, Departemen Kesehatan Republik Indonesia menyatakan bahwa prevalensi hipertensi di Indonesia cukup tinggi. Hasil Riset Kesehatan Dasar (Riskesdas) tahun 2007 menunjukkan prevalensi hipertensi di Indonesia sebesar $31,7 \%$. Selain itu, akibat yang ditimbulkannya menjadi masalah kesehatan masyarakat.

Peran penting yang menentukan keberhasilan dalam pengobatan hipertensi adalah pemahaman, pengetahuan, dan kepatuhan pasien. Berdasarkan penelitian Mulyasih (2012) mengenai pengaruh konseling apoteker terhadap hasil terapi pasien hipertensi di poliklinik penyakit dalam RSUD Kraton kabupaten Pekalongan dengan menggunakan media leaflet, dari 75 pasien, kelompok perlakuan $(\mathrm{N}=39)$ mengalami penurunan tekanan darah yang bermakna yaitu sistolik sebesar $11,28 \pm 8,33 \mathrm{mmHg}$ dan diastolik sebesar 7,18 $\pm 6,86 \mathrm{mmHg}$ [2], sedangkan penelitian Karau (2013) mengenai pengaruh layanan pesan singkat telepon selular pada tingkat kepatuhan terhadap pasien hipertensi di Family Medicine Clinic memberikan hasil pada pengukuran tekanan darah diastolik berkurang dari rata-rata $87,9 \mathrm{mmHg}$ menjadi $81,8 \mathrm{mmHg}$ pada kelompok uji dibandingkan dengan kelompok kontrol yang mengalami penurunan tekanan diastolik dari $86,8 \mathrm{mmHg}$ menjadi $82 \mathrm{mmHg}$. Pengukuran tekanan darah sistolik berkurang dari rata-rata 141,4 $\mathrm{mmHg}$ menjadi 131,9 mmHg pada kelompok uji, sementara terjadi peningkatan tekanan darah pada kelompok kontrol dari 140,4 mm $\mathrm{Hg}$ menjadi $142,5 \mathrm{mmHg}$ [3]. Oleh karena itu, perlu dilakukan penelitian untuk mengetahui efektivitas antara penggunaan media leaflet sebagai sarana pemberian informasi dan perlakuan reminderkepada pasien hipertensi agar dapat meningkatan 
pemahaman, pengetahuan dan kepatuhan pasien yang terkait perilaku pasien sehingga dapat mendukung keberhasilan dalam pengobatan hipertensi di RSUD A. W Sjahranie Samarinda.

\section{METODE PENELITIAN}

Penelitian ini adalah studi eksperimen dengan rancangan systematic random sampling. Penelitian menggunakan dua kelompok, kelompok pertama diberikan leaflet dan kelompok kedua diberikan reminder.

Populasi penelitian adalah semua pasien penderita hipertensi yang berada di instalasi rawat jalan di RSUD A.W Sjahranie. Sampel penelitian adalah pasien hipertensi yang termasuk dalam kriteria inklusi. Kriteria inklusi adalah semua pasien hipertensi dengan atau tanpa penyakit penyerta yang berada di instalasi rawat jalan di RSUD A.W Sjahranie selama periode Desember 2014 - Januari 2015, dan pasien tersebut memiliki rekam medik yang memuat tentang deskripsi pasien meliputi usia, jenis kelamin, dan tekanan darah, berusia 20-65 tahun, memiliki akses untuk dapat menerima layanan pesan pendek (SMS) melalui ponsel, tidak sedang hamil, bersedia menjadi sampel penelitian. Kriteria eksklusi adalah pasien yang didiagnosa hipertensi yang berada di instalasi rawat jalan tidak memiliki data rekam medik yang lengkap atau sulit dibaca, tidak memiliki akses untuk dapat menerima layanan pesan pendek (SMS) melalui ponsel dan pasien sedang hamil.

Penelitian ini dilakukan dengan pengambilan data secara prospektif. Pengumpulan data dilakukan dengan mencatat beberapa parameter yaitu nama, usia, jenis kelamin, pekerjaan, pendidikan terkhir, riwayat keluarga, riwayat merokok, tekanan darah, nama obat, frekuensi pemberian obat dan jumlah obat. Sampel yang termasuk kriteria inklusi dibagi menjadi dua kelompok uji, kelompok uji 1 diberi leaflet dan kelompok uji 2 diberi reminder. Hasil pengamatan dilakukan selama satu bulan dengan mencatat tekanan darah dari data rekam medik pasien dan jumlah obat yang tersisa dari komunikasi langsung dengan pasien, kemudian data yang didapatkan dianalisis dengan menggunakan statistik.

\section{HASIL DAN PEMBAHASAN}

\section{Karakteristik Pasien Hipertensi}

Tabel 1. Distribusi pasien hipertensi berdasarkan usia dan jenis kelamin

\begin{tabular}{|c|c|c|c|c|}
\hline \multirow{2}{*}{ Usia (Tahun) } & \multicolumn{2}{|c|}{ Jenis kelamin (orang) } & \multirow{2}{*}{$\begin{array}{l}\text { Jumlah } \\
\text { (orang) }\end{array}$} & \multirow{2}{*}{$\begin{array}{c}\text { Presentase } \\
(\%)\end{array}$} \\
\hline & Perempuan & Laki-laki & & \\
\hline $18-40$ & 0 & 2 & 2 & 4 \\
\hline $41-65$ & 26 & 20 & 46 & 92 \\
\hline$>65$ & 1 & 1 & 2 & 4 \\
\hline
\end{tabular}


Hasil tabel 1 menunjukkan perempual lebih banyak menderita hipertensi dibandingkan laki-laki, jenis kelamin dapat mempengaruhi tekanan darah, hal tersebut termasuk peran potensial dari hormon yaitu estrogen. Pada laki-laki hanya memiliki sedikit hormon estrogen bila dibandingkan dengan perempuan, tetapi ketika memasuki masa menopause produksi hormon estrogen oleh perempuan menurun atau tidak lagi diproduksi [4]. Pada perempuan terdapat variasi umur memasuki masa menopause, yaitu dapat terjadi pada usia 40 tahun atau 56 tahun [5]. Hormon estrogen meningkatkan kadar angiotensinogen, dan menurunkan kadar renin, aktivitas angiotensin convertingenzyme (ACE), selain itu kadar endotelin dan stress oksidatif meningkat memasuki masa menopause, hal tersebut dapat mempengaruhi tekanan darah melalui peningkatan reabsorpsi natrium dan vasokonstriksi [4]. Pada umumnya, tekanan darah bertambah secara perlahan dengan bertambahnya usia. Hal ini disebabkan oleh berubahnya struktur pembuluh darah besar, sehingga dinding pembuluh darah menjadi kaku dan lumen menjadi lebih sempit [6]. Dinding pembuluh darah yang mengeras atau kaku membutuhkan tekanan darah sistolik yang lebih tinggi agar darah dapat melewati pembuluh darah yang mengeras dibandingkan dinding pembuluh darah yang lebih elastis [7].

Tabel 2. Distribusi pasien hipertensi berdasarkan riwayat hipertensi

\begin{tabular}{ccc}
\hline Riwayat Hipertensi & Jumlah (orang) & Presentase (\%) \\
\hline Ada riwayat & 32 & 64 \\
Tidak ada riwayat & 18 & 36 \\
\hline
\end{tabular}

Hasil penelitian pada tabel 2 sejalan dengan penelitian Shook (2012) yang menyatakan bahwa kelompok uji yang memiliki riwayat hipertensi $20 \%$ lebih tinggi terkena hipertensi dibandingkan kelompok uji yang tidak memiliki riwayat hipertensi [8]. Fenotipe resiko kardiovaskular dapat diwariskan oleh orangtua terutama ibu, faktor dari ibu seperti interaksi antara genom janin dengan lingkungan yang ditentukan oleh fisiologi dari ibu saat pertumbuhan janin [9].

Tabel 3. Distribusi pasien hipertensi berdasarkan riwayat merokok

\begin{tabular}{ccc}
\hline Riwayat Merokok & Jumlah (orang) & Presentase (\%) \\
\hline Pernah merokok & 7 & 14 \\
Tidak pernah merokok & 43 & 86 \\
\hline
\end{tabular}

Otak bereaksi terhadap nikotin dengan memberi sinyal pada kelenjar adrenal untuk melepas epinefrin (adrenalin). Hormon yang kuat ini akan menyempitkan pembuluh darah dan memaksa jantung untuk bekerja lebih berat karena tekanan yang lebih tinggi [10]. Hasil penelitian pada tabel 3 didapatkan bahwa pasien hipertensi yang memiliki riwayat sebagai perokok sebanyak 7 orang (14\%) sedangkan yang tidak memiliki riwayat sebagai perokok sebanyak 43 orang (86\%). Hasil penelitian berbeda dengan teori, bahwa pasien hipertensi sebagian 
besar adalah perokok. Hal tersebut terjadi karena subjek penelitian kebanyakan berjenis kelamin perempuan, sedangkan perempuan di lokasi penelitian secara budaya jarang sekali ada yang merokok.

Tabel 4. Distribusi Pasien berdasarkan Pekerjaan

\begin{tabular}{ccc}
\hline Jenis Pekerjaan & Jumlah (orang) & Presentase (\%) \\
\hline PNS & 10 & 20 \\
Swasta & 5 & 10 \\
Wiraswasta & 12 & 24 \\
Tidak bekerja & 23 & 46 \\
\hline
\end{tabular}

Hasil tabel 4 menunjukkan bahwa pasien yang memiliki pekerjaan lebih banyak yang mengalami hipertensi dibandingkan pasien yang tidak memiliki pekerjaan. Hal tersebut telah sesuai teori karena menurut penelitian Sigalingging (2011) sesorang yang memiliki pekerjaan umumnya sering lembur, kurang istirahat dan mengalami stress atau tertekan [11]. Dalam kondisi tertekan, hormon adrenalin dilepaskan ke aliran darah sehingga menyebabkan peningkatan tekanan darah karena terjadi penyempitan pembuluh darah yang mengakibatkan peningkatan tekanan darah [10]. Pasien yang tidak bekerja sebagian besar adalah ibu rumah tangga dan pensiunan. Seseorang yang tidak bekerja atau hanya sebagai ibu rumah tangga memiliki resiko menderita hipertensi. Hal ini disebabkan oleh kurangnya aktivitas yang dilakukan, dimana kebanyakan hanya berdiam diri dirumah dengan rutinitas yang membuat suntuk. Individu yang aktivitasnya rendah berisiko terkena hipertensi 30-50\% dari individu yang aktif [12].

Tabel 5. Distribusi Pasien berdasarkan Pendidikan Terakhir

\begin{tabular}{ccc}
\hline Pendidikan Terakhir & Jumlah (orang) & Presentase $(\%)$ \\
\hline SD & 25 & 50 \\
SMP & 14 & 28 \\
SMA & 3 & 6 \\
DIII & 2 & 4 \\
S1 & 6 & 12 \\
\hline
\end{tabular}

Hasil tabel 5 menunjukkan bahwa pasien hipertensi terbanyak dengan pendidikan terakhir adalah SD (50\%). Hal tersebut telah sejalan dengan penelitian Agrina dkk (2011) tingkat pendidikan dapat mempengaruhi kemampuan dan pengetahuan seseorang dalam menerapkan perilaku hidup sehat, terutama mencegah penyakit hipertensi. Semakin tinggi tingkat pendidikan maka semakin tinggi pula kemampuan seseorang dalam menjaga gaya hidup. Hal tersebut karena semakin tinggi pendidikan seseorang, maka makin mudah menerima informasi 
sehingga makin banyak pula pengetahuan yang dimiliki daripada pasien dengan tingkat pendidikan yang rendah [12].

\section{Pengaruh pemberian Leaflet dan Reminder terhadap Tekanan Darah dan Kepatuhan Konsumsi Obat dan Tahap Perilaku pada Pasien Hipertensi}

Tabel 6. Perubahan tekanan darah sistolik dan diastolik pada kelompok intervensi reminder dan leaflet sebelum dan sesudah perlakuan.

\begin{tabular}{|c|c|c|c|c|}
\hline \multirow{2}{*}{ Variabel } & \multicolumn{2}{|c|}{ Kelompok intervensi reminder } & \multicolumn{2}{|c|}{ Kelompok intervensi leaflet } \\
\hline & Mean \pm SD & $\mathrm{p}$ Value & Mean \pm SD & $\mathrm{p}$ Value \\
\hline \multicolumn{5}{|c|}{ Tekanan darah sistolik (mmHg) } \\
\hline Pre intervensi & $140,80 \pm 13,204$ & 0,000 & $141,60 \pm 14,341$ & 0,007 \\
\hline Post intervensi & $124,40 \pm 12,275$ & & $130,40 \pm 13,989$ & \\
\hline Selisih & $16,4 \pm 0,749$ & & $11,20 \pm 0,352$ & \\
\hline \multicolumn{5}{|c|}{ Tekanan darah diastolik (mmHg) } \\
\hline Pre intervensi & $84,00 \pm 10,00$ & 0,026 & $83,60 \pm 6,377$ & 0,017 \\
\hline Post intervensi & $80,00 \pm 5,774$ & & $79,20 \pm 8,124$ & \\
\hline Selisih & $4,00 \pm 4,226$ & & $4,40 \pm 1,747$ & \\
\hline
\end{tabular}

Keterangan: Uji Wilcoxon bermakna $(p<0,05)$

Tabel 7. Perbedaan pengaruh pemberian leaflet dan reminder terhadap tekanan darah

\begin{tabular}{lcccc}
\hline Kelompok & \multicolumn{2}{c}{ Perubahan Tekanan Darah Sistolik } & \multicolumn{2}{c}{ Perubahan Tekanan Darah Diastolik } \\
\cline { 2 - 5 } Intervensi & Mean \pm SD & $\mathrm{p}$ Value & Mean \pm SD & $\mathrm{p}$ Value \\
\hline Leaflet & $11,200 \pm 18,556$ & 0,424 & $4,40 \pm 8,205$ & 0,831 \\
Reminder & $16,400 \pm 13,503$ & & $4,00 \pm 8,164$ & \\
\hline
\end{tabular}

Keterangan: Uji Mann-Whitney U bermakna $(\mathrm{p}<0,05)$

Hasil penelitian pada tabel 6 didapatkan perubahan yang signifikan dalam penurunan tekanan darah sitolik dan diastolik setelah pemberian intervensi leaflet maupun reminder, tetapi pada tabel 7 terlihat tidak ada perbedaan yang signifikan dalam rata-rata jumlah penurunan tekanan sitolik $(\mathrm{p}=0,424)$ dan diastolik $(\mathrm{p}=$ 0,831 ) setelah pemberian intervensi leaflet maupun reminder. Hal tersebut disebabkan subjek penelitian dalam kelompok intervensi leaflet menerima informasi berupa terapi non farmakologi dan farmakologi yang dapat menunjang efektivitas terapi hipertensi. Leaflet berisikan tentang saran untuk rutin mengukur tekanan darah di rumah sakit atau klinik terdekat, rutin mengkonsumsi obat, bahaya tentang hipertensi, perubahan gaya hidup seperti olahraga, mengatur pola makan, berhenti konsumsi alkohol dan rokok serta pembatasan konsumsi garam, sehingga walaupun dalam \% kepatuhan konsumsi obat lebih rendah daripada kelompok intervensi reminder, tetapi karena subjek penelitian dapat menerapkan informasi yang terdapat di media leaflet maka terapi non farmakologi dapat menunjang terapi farmakologi yang menghasilkan penurunan tekanan darah sistolik dan diastolik 
signifikan dari tekanan darah sebelum diberikan leaflet. Pada kelompok intervensi reminder subjek penelitian memiliki perbedaan yang signifikan dalam penurunan tekanan darah sistolik dan diastolik setelah perlakuan. Hal tersebut sebanding dengan tingginya tingkat kepatuhan pasien dalam konsumsi obat. JNC VIII menyatakan bahwa jangka waktu terapi antihipertensi adalah seumur hidup, terapi antihipertensi bertujuan untuk menstabilkan tekanan darah sehingga menurunkan mortalitas dan morbiditas yang berhubungan dengan kerusakan organ target seperti penyakit kardiovaskular, cerebrovaskular, gagal jantung, dan penyakit ginjal. Kepatuhan minum obat berperan dalam mengontrol tekanan darah dan mencegah terjadinya komplikasi hipertensi [13].

Tabel 8. Perbedaan kepatuhan konsumsi obat pada subjek penelitian

\begin{tabular}{lcc}
\hline \multirow{2}{*}{ Intervensi } & \multicolumn{2}{c}{$\%$ Kepatuhan Konsumsi Obat } \\
\cline { 2 - 3 } \multicolumn{1}{c}{ Leaflet } & Mean \pm SD & $\mathrm{p}$ Value \\
Reminder & $86,960 \pm 10,628$ & 0,000 \\
\hline
\end{tabular}

Keterangan: Uji Mann-Whitney U bermakna $(\mathrm{p}<0,05)$

Tabel 8 menunjukkan perbedaan yang signifikan terhadap kepatuhan konsumsi obat pada kelompok intervensi leaflet dan reminder. Hal tersebut disebabkan pada kelompok intervensi reminder, subjek penelitian mendapatkan pesan singkat setiap harinya untuk mengingatkan pasien dalam mengkonsumsi obat. Pesan singkat berisikian pengingat dan motivasi pada pasien agar rutin untuk konsumsi obat hipertensi yang telah diberikan. Pesan pengingat berisikan nama obat, dosis obat, jumlah obat, frekuensi obat, rute pemberian obat, dan waktu konsumsi obat.Sedangkan pada kelompok intervensi leaflet, subjek penelitian hanya diberi informasi saat konseling pada awal pertemuan untuk rutin mengkonsumsi obat hipertensi. Secara psikologis, subjek penelitian pada kelompok intervensi reminder lebih tinggi kepatuhan konsumsi obatnya karena setiap harinya mendapat perintah untuk konsumsi obat, sedangkan subjek penelitian pada kelompok intervensi leaflet setelah menerima informasi tidak langsung menerapkan perilaku untuk rutin minum obat dan perlu waktu yang cukup lama untuk terlebih dahulu memahami informasi yang telah diberikan.

Tabel 9. Tahap Perilaku Pasien setelah Pemberian Leaflet dan Reminder

\begin{tabular}{|c|c|c|c|}
\hline \multirow[b]{2}{*}{ Tahap Perilaku Pasien } & \multicolumn{2}{|c|}{ Jumlah Subjek Penelitian } & \multirow[b]{2}{*}{$\begin{array}{c}\% \text { Rata-Rata Kepatuhan } \\
\text { Pasien }\end{array}$} \\
\hline & $\begin{array}{c}\text { Kelompok } \\
\text { intervensi } \\
\text { leaflet }\end{array}$ & $\begin{array}{c}\text { Kelompok } \\
\text { intervensi } \\
\text { reminder }\end{array}$ & \\
\hline Precontemplation stage & 0 & 0 & $0 \%(0-24 \%)$ \\
\hline Contemplation stage & 3 & 0 & $66 \%(25-75 \%)$ \\
\hline Preparation stage & 22 & 25 & $94 \%(76-100 \%)$ \\
\hline
\end{tabular}


Tabel 9 menunjukkan bahwa setelah pemberian leaflet dan reminder tidak ada subjek penelitian yang berada pada tahap perilaku precontemplation stage yang ditandai dengan tingkat $\%$ rata-rata kepatuhan konsumsi obat adalah $0 \%$. Hal tersebut terjadi karena pada kelompok intervensi leaflet maupun reminder pasien diberikan informasi mengenai penyakitnya, komplikasi yang terjadi, terapi farmakologi dan non farmakologi, sehingga tahap perilaku pasien meningkat ke tahap perilaku contemplation stage dimana sebanyak 3 orang subjek penelitian berada pada tahap tersebut. Tahap perilaku contemplation stage yaitu tahap dimana pasien telah memahami informasi yang diberikan melalui media leaflet maupun reminder sehingga pasien mulai menyadari perlu dilakukanya perubahan gaya hidup ditandai dengan tingkat \% rata-rata kepatuhan konsumsi obat yaitu $66 \%$. Sedangkan 47 subjek penelitian berada pada tahap perilaku preparation stage yaitu tahap dimana pasien yang telah memahami dan menyadari penyakitnya dari informasi yang diberikan melalui media leaflet maupun reminder mulai menerapkan perubahan gaya hidup yang ditandai dengan tingginya $\%$ rata-rata kepatuhan konsumsi obat yaitu $94 \%$,

\section{KESIMPULAN}

Karakteristik pasien hipertensi di instalasi rawat jalan RSUD A.W Sjahranie adalah $54 \%$ perempuan, $92 \%$ pada usia 41-65 tahun, $86 \%$ tidak merokok dan 64 $\%$ memiliki riwayat keluarga yang mengalami hipertensi, $46 \%$ tidak bekerja dan $50 \%$ pendidikan terakhir sekolah dasar (SD). Tidak terdapat perbedaan tekanan darah sistolik $(\mathrm{p}=0,424)$ dan tekanan darah diastolik $(\mathrm{p}=0,831)$ antara subjek pada kelompok leaflet dan subjek pada kelompok reminder. Rata-rata kepatuhan pasien dalam konsumsi obat hipertensi yaitu 86,96\% pada kelompok intervensi leaflet dan $98,32 \%$ pada kelompok intervensi reminder $(\mathrm{p}=0,000)$. Tidak terdapat subjek penelitian pada tahap perilaku precontemplation stage dengan $\%$ rata-rata kepatuhan $0 \%, 3$ subjek penelitian pada tahap perilaku contemplation stage dengan $\%$ rata-rata kepatuhan $67 \%$ dan 47 subjek penelitian pada tahap perilaku preparation stage dengan $\%$ rata-rata kepatuhan $94 \%$.

\section{DAFTAR PUSTAKA}

[1] Dipiro J.T, Robert L.T, Gary C.Y, Gary R.M, Barbara G.W, Michael P. 2005. Pharmacotherapy: A Pathophysiologic Approach Sixth Edition. MC GRAWHILL Medical Publishing Division: Unites State of America.

[2] Mulyasih, A B, Djoko Wahyono, I Dewa Putu Pramantara. 2012. Pengaruh Konseling Apoteker Terhadap Hasil Terapi Pasien Hipertensi di Poliklinik Penyakit Dalam RSUD Kraton Kabupaten Pekalongan. Jurnal Farmasains 2 (1).

[3] Karau, B. 2013. Effect of mobile phone short message service on adherence rates to antihypertensives at the Family Medicine Clinic. Aga Khan University: East Africa. 
[4] Gudmundsdottir, H., Hoieggen, A., Stenehjem, A., Waldum, B.,Os, I., 2012. Hypertension in Women: Latest Findings and Clinical Implications. Ther Adv Chronic Dis 3 (3):137-146.

[5] Wratsangka, Raditya. 1999. Pemberian Terapi Sulih Hormon Sebagai Upaya Meningkatkan Kesehatan Wanita Upaya Meningkatkan Kesehatan Wanita Monopause. Jurnal Kedokteran Trisakti 18 (3).

[6] Gumi, V.C, Larasant L.P.F, N.N.W. 2013. Identifikasi Drug Related Problems pada Penanganan Pasien Hipertensi di UPT Puskesmas Jembrana. Jurnal Farmasi Udayana 2 (3).

[7] Wisudawan, Agus, Prasojo Pribadi dan Puspita Septi. Gambaran Penggunaan Antihipertensi di Poliklinik Penyakit Dalam RSUD Tidar Kota Magelang Periode Januari - Juni 2012. Jurnal Fakultas Ilmu Kesehatan UMM 3 (2).

[8] Shook, Robin P., Duck C.L., Xuemei Sui., Vivek Prasad, Steven P.H. 2012. Cardiorespiratory Fitness Reduces the Risk of Incident Hypertension Associated with a Parental History of Hypertension. American Heart of Association 59: 1220-1224.

[9] Liu, Jufen., Michikazu Sekine., Takashi Tatsue., Shimako Hamnishi., Yuko Fujimura and Xiaoying Zheng. 2014. Family History of Hypertension and the Risk of Overweight in Japanese Children: Results From the Toyama Birth Cohort Study. Journal Epidemiol 24 (4): 304-311.

[10] Sugiharto, Aris. 2010. Faktor- Faktor Risiko Hipertensi Grade II pada Masyarakat (Studi Kasus di Kabupaten Karanganyar). Jurnal UNDIP 3 (1).

[11] Sigalingging, Ganda. 2011. Karakteristik Penderita Hipertensi di Rumah Sakit Umum Herna Medan. Jurnal Universitas Darma Agung 1 (1).

[12] Agrina, Sunarti S. S, Riyan Hairitam. 2011. Kepatuhan Lansia Penderita Hipertensi dalam Pemenuhan Diet Hipertensi. Jurnal SOROT Universitas Riau $6(1)$.

[13] Hairunisa. 2014. Hubungan Tingkat Kepatuhan Minum Obat dan Diet dengan Tekanan Darah terkontrol pada Penderita Hipertensi Lansia di Wilayah Kerja Puskesmas Perumnas I Kecamatan Pontianak Barat. Jurnal Mahasiswa PSPD FK Universitas Tanjungpura 1 (1). 